\title{
Integrated control chart system for time-between-events monitoring in a multistage manufacturing system
}

M. Shamsuzzaman • Min Xie • Thong Ngee Goh •

Hai Yun Zhang

Published online: 3 April 2008

(C) Springer-Verlag London Limited 2008

Erratum to: Int J Adv Manuf Technol

DOI 10.1007/s00170-007-1338-8

Unfortunately, the spelling of the author's names was incorrect.

The correct names should read Min Xie, Thong Ngee Goh and Hai Yun Zhang.

The online version of the original article can be found at http://dx.doi. org/10.1007/s00170-007-1338-8.

M. Shamsuzzaman $(\bowtie) \cdot$ M. Xie $\cdot$ T. N. Goh $\cdot$ H. Y. Zhang

Department of Industrial and Systems Engineering,

National University of Singapore,

Kent Ridge Crescent,

Singapore 119260, Singapore

e-mail: shams@pmail.ntu.edu.sg 